\title{
POTENTIAL OF THERMAL SPRAYED TECHNOLOGIES FOR MAINTENANCE AND REPAIR OF CONVENTIONAL AND NUCLEAR POWER PLANTS COMPONENTS
}

\author{
'Šárka HOUDKOVÁ, ${ }^{2} Z$ deněk ČESÁNEK, ${ }^{3}$ Petra ŠULCOVÁ, ${ }^{4}$ Anna KESLOVÁ, \\ ${ }^{5}$ Kateřina LENCOVÁ, ${ }^{6}$ Josef DULIŠKOVIČ \\ ${ }^{1}$ Research and Testing Institute Plzeň, Plzeň, Czech Republic, EU, houdkova@vzuplzen.cz \\ ${ }^{2}$ Research and Testing Institute Plzeň, Plzeň, Czech Republic, EU, cesanek@vzuplzen.cz \\ ${ }^{3}$ Research and Testing Institute Plzen̆, Plzeň, Czech Republic, EU, sulcova@vzuplzen.cz \\ ${ }^{4}$ Research and Testing Institute Plzen̆, Plzeň, Czech Republic, EU, keslova@vzuplzen.cz \\ ${ }^{5}$ Research and Testing Institute Plzeň, Plzeň, Czech Republic, EU, lencova@vzuplzen.cz \\ ${ }^{6}$ Research and Testing Institute Plzeň, Plzeň, Czech Republic, EU, duliskovic@vzuplzen.cz
}

https://doi.org/10.37904/metal.2020.3541

\begin{abstract}
The thermal spray technologies are versatile methods of deposition of thick coatings on the components surfaces. Based on spraying technology principle, various materials and coating thicknesses can be deposited. Some spraying technologies, as mobile systems, have the capability to be used directly on-site. Typically, the Twin Wire Arc Spraying systems (TWAS) are utilized to spray the large-scale constructions to protect them from corrosion. Also, one of the latest spraying technologies, Cold Spray, is nowadays being developed to serve as mobile system. Both technologies offer the possibility to spray coatings up to several millimeters thick, which makes them suitable for renovation of worn or corroded material in higher volumes. In the manuscript, the used methods and results achieved so far in the frame of National Center for Energy, are presented and compared with respect to the relationships between coatings microstructure, mechanical and functional properties. Both technologies proved its potential to deposit protective coatings, applied on conventional and nuclear power plants components.
\end{abstract}

Keywords: Thermal spray, power industry, renovation, TWAS, Cold Spray

\section{INTRODUCTION}

The thermally sprayed coatings represent a group of technologies, enabling to deposit the material on the pretreated substrate surface. Usually, the aim of deposition is to create a continuous coating with specific properties, typically wear or corrosion resistance, to increase the lifetime of coated parts. In some specific cases, these technologies can be used also for renovation of worn or corroded components, when the missing material is refilled by spraying technologies. The needs of power industry include both - the coating of component during primary production, as well as the renovation of already used components, built into the power plants. Transportation of such built-in equipment to spraying workshops is often not possible. In these cases, portable deposition technologies find their use. Moreover, the amount of worn material can locally exceed the limits of thickness, that can be deposited by the majority of spraying technologies. To find a solution for such situations, an extensive research program was designed in the frame of National Centre for Energy (project of Technology Agency of the Czech Republic). Two thermal spray technologies, allowing spraying of coatings with high thickness and simultaneously being potentially portable, were chosen to spray testing speciments and later to prove its potential for spraying of real component. 
The Twin Wire Arc Spraying technology (TWAS) is a versatile and cheap technology for deposition of namely metal coatings [1]. Thanks to its high deposition rates it is used for spraying of large areas. It is often used to protect e.g. bridge structures from corrosion. The principle of the technology is as follows: the material in the form of wires is fed into the spraying gun. Between the tips of the wires the electric arc is burn, melting the wire material. Simultaneously the compressed air is fed to the gun. The air stream carries molten drops of material toward the coated surface, where it solidified. During spraying, the molten droplets creates oxidized envelopes on its surface in the air atmosphere. After impacting the substrate, the oxides became part of the coating's microstructure. The high amount of oxides inclusions, as well as presence of cracks and decohesion between the particles, are significant for TWAS sprayed coatings. If the spraying parameters are chosen properly, this technology enables to create coatings with thicknesses up to several millimeters. One of the latest members of thermal spray family, Cold Spray (CS) is based on supersonic velocities of impacting particles [1]. The metal material in form of fine particles, is heated up to the temperatures far below to its melting point to increase its plasticity and then accelerated to the substrate in velocities reaching multiples of sound speed. The high kinetic energy is during the impact transformed into deformation and temperature, enabling to create local micro-weld on the particle boundary. The final coating is very dense and homogenous, with high cohesive and adhesive strength. Low deposition temperature, together with presence of inert gases ( $\mathrm{Ar}$ and $\mathrm{N}$ or $\mathrm{He}$ ) in the particle stream, makes the coating free of oxides. Thanks to the compressive stress in the coating, there are no limits for the thickness of deposited layers. With respect to the intended application requirements, the $\mathrm{Fe}$ - and $\mathrm{Ni}$ based materials were chosen to be deposited onto the testing specimens. Its composition varied to ensure sufficient cavitation and erosion resistance and high corrosion resistance even in the aggressive environment of solid fuel boilers or in the environment of geothermal powerplant [2,3]. The experimental program was designed to compare the corrosion and mechanical resistance of selected $\mathrm{Fe}$ and $\mathrm{NiCr}$-based coatings, deposited by TWAS and CS technologies, recommend as the most effective and economical solutions for intended application; and to verify the applicability in under the real conditions even for built-in components. The aim of the paper is to present some of the results, achieved during the first year of project solution and show the potential of protective coatings application in harsh environment.

\section{EXPERIMENTAL}

\subsection{Specimens preparation}

The first sets of coatings specimens were sprayed by TWAS SmartArc Oerlicon Metco spraying system. The substrate material and dimensions were set in agreement to requirements of each test provided: the specimens for high temperature corrosion test in aggressive salts were deposited on the corrosion-resistant P91 steel, while the rest of the specimens was sprayed on carbon steel. The substrate surface was cleaned and grit blasted prior to the spraying $\left(\mathrm{Al}_{2} \mathrm{O}_{3} ; \mathrm{F} 22\right)$. The coating materials are summarized in the Table 1 . The previously optimized spraying parameters were used to spray coatings reaching thicknesses between 500 and $750 \mu \mathrm{m}$.

Table 1 Coatings deposited by TWAS spraying

\begin{tabular}{|c|c|c|}
\hline Coating no. & $\begin{array}{c}\text { Composition } \\
\text { (wt\%) }\end{array}$ & $\begin{array}{c}\text { Average thickness } \\
\text { ( } m m)\end{array}$ \\
\hline TWAS 1 & Fe28Cr4B2Si2Mn0.1C & $0.74 \pm 0.03$ \\
\hline TWAS 2 & Fe18Cr18Ni4.6C2Al2V0.97Mn & $0.71 \pm 0.04$ \\
\hline TWAS 3 & Ni25Cr10C3Mo3Si2Fe0.8Al & $0.51 \pm 0.1$ \\
\hline TWAS 4 & Ni20Cr & $0.63 \pm 0.03$ \\
\hline TWAS 5 & Ni21Cr9Mo4(Ta+Nb) & $0.58 \pm 0.03$ \\
\hline TWAS 6 & Ni45Cr1Ti & $0.56 \pm 0.13$ \\
\hline
\end{tabular}


The second sets of specimens were sprayed by Cold Spray technology, using Impact Spray system of Impact Innovation company. The Ni20Cr powder (Ospray powder, Sandvik) in two different grain size (10-32) $\mu \mathrm{m}$ and $(5-25) \mu \mathrm{m}$ was deposited onto the carbon steel substrate $(100 \times 100 \times 5) \mathrm{mm}$. The uniform, previously optimized spraying parameters were set, except of variation of spraying angle $\left(90^{\circ}\right.$ and $\left.45^{\circ}\right)$ and deposition distance $(15$, 30 and $45 \mathrm{~mm}$ ). The intended cold sprayed coating thickness was $1 \mathrm{~mm}$. The coated specimen was later cut on pieces based on the needs of each test.

\subsection{Testing procedures}

The coatings microstructure was evaluated in the coatings' cross sections, grinded and polished by standard metallographic procedure. The optical microscopy was used to measure the coating thickness and to evaluate their microstructure. The Vickers microhardness HV0.3 was measured in the coatings' cross sections. At least 7 indents were made and the average value is reported. The adhesive/cohesive strength of the coatings was evaluated by tensile test method, in accordance to ASTM C633-01. For each coating, four measurements were realized, the average value is reported. The abrasive wear resistance was measured using the Dra sand/Rubber Wheel test in accordance to ASTM G-65. For each coating, three tests were realized, the average value is reported. After the wear tests, the wear mechanism was analysed by SEM. The solid particle erosion was tested using centrifugal erosion test. The impact angle of erosive media $\left(\mathrm{Al}_{2} \mathrm{O}_{3} ; \mathrm{F} 70\right)$ varied between $12^{\circ}$ $90^{\circ}$. After the test, the wear mechanism was analysed by SEM. The high temperature corrosion test was realized in the aggressive environment of $\mathrm{Na}_{2} \mathrm{SO}_{4} \mathrm{Fe}_{2}\left(\mathrm{SO}_{4}\right)_{3}$. The test condition is described in more detail in [5]. After the test, the corrosion mechanism was analysed by SEM.

\section{RESULTS AND DISSCUSION}

The microstructure of sprayed coatings contains the features typical for used deposition technique.

As a representative of TWAS technology, the microstructure of TWAS sprayed Fe-based coating (Figure 1a) and $\mathrm{NiCr}$ coating (Figure 1b) can be seen in the Figure 1. The difference in size of individual particles, size, distribution and number of pores and presence of cracks between the evaluated coatings from different materials are obvious. The dominant effect can be attributed to the type of sprayed material, although the spraying parameters, namely the pressure of carrier gas (air) plays also its role. The higher the pressure of air is, the finer the splats are.

The microstructure of CS NiCr coatings, deposited perpendicularly to substrate surface (Figure 2a) and at the angle of $45^{\circ}$ (Figure $\mathbf{2 b}$ ) can be seen in the Figure 2. The perpendicularly sprayed coating is almost pore-free and without visible boundaries between individual particles. In the coating, sprayed at the angle of $45^{\circ}$, some pores can be recognized, but their amount is far less compared to the TWAS NiCr coating (Figure 1b).

The measured HV0.3 microhardness values of TWAS sprayed coatings and their cohesive strength are shown in the Figure 3. Adhesion of all tested coatings to the substrate was higher than the coatings cohesive strength. The TWAS 1 coating has the highest microhardness, while its cohesive strength is the lowest. It suggests the possible high amount of oxides inclusion in the coatings 'microstructure, decreasing the cohesion between individual particles. The high microhardness results also from the high content of carbon in the coating composition, strengthening the coating by precipitation of hard particles. On the other hand, the lowest microhardness was measured for Ni20Cr coating, consisting from Ni solid solution.

The microhardness of cold sprayed Ni20Cr coatings varied between 393 and $420 \mathrm{HV}$ 0.3. The lowest value with the highest scatter was recorded for the coating deposited at $45^{\circ}$ angle. The higher scatter and lowered microhardness value are related to the coating's higher porosity. The highest microhardness was reached by the coating, deposited from finer particles. In comparison to TWAS sprayed NiCr coating (cca $230 \mathrm{HV} 0.3$ ), the influence of used deposition technology can be seen. Both the effect of high porosity of TWAS sprayed 
coatings and the effect of deformation strengthening during the deposition by high kinetic cold spray deposition process plays its role.
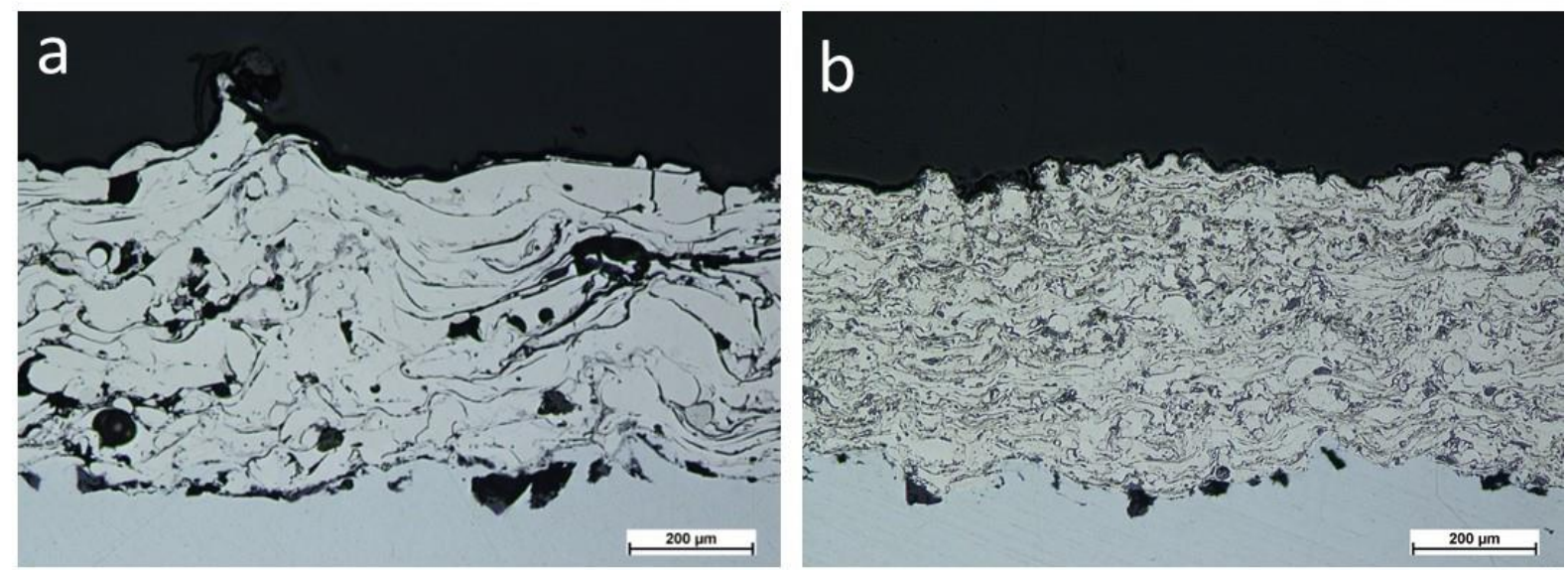

Figure 1 Cross section microstructure of TWAS 2 (a) and TWAS 4 (b) coating
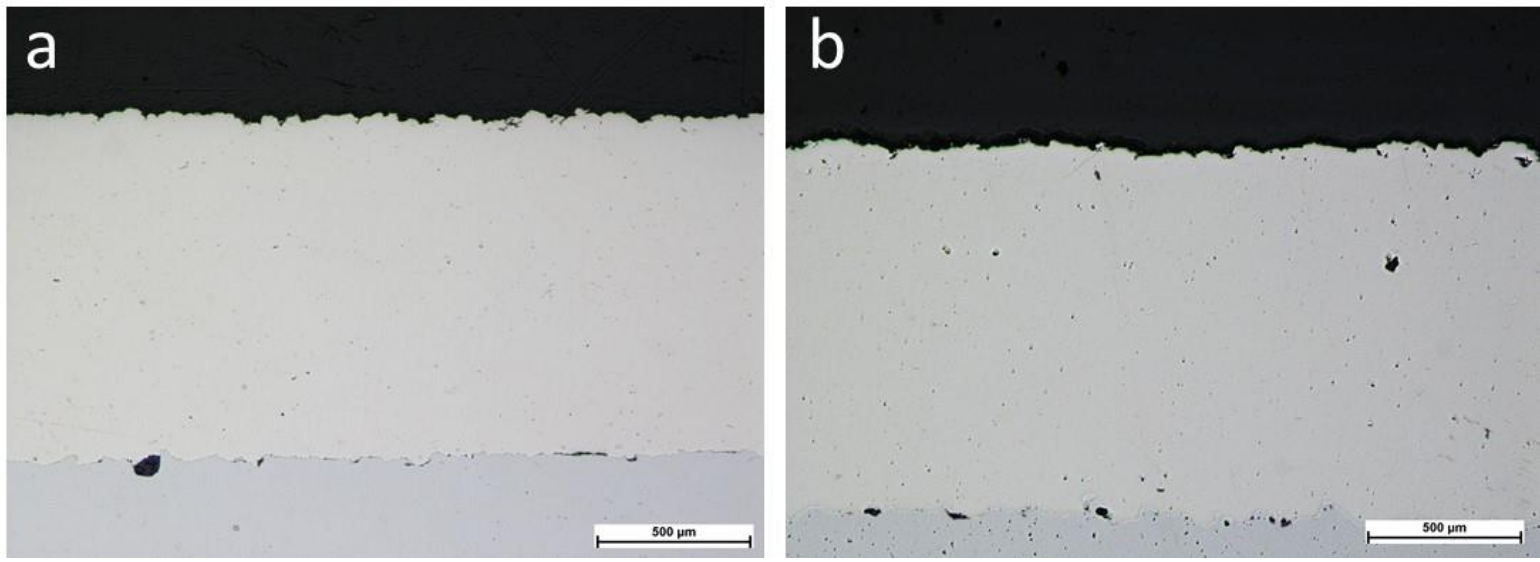

Figure 2 Cross section microstructure of cold sprayed coating deposited perpendicularly to the surface (a) and at $45^{\circ}$ angle (b)

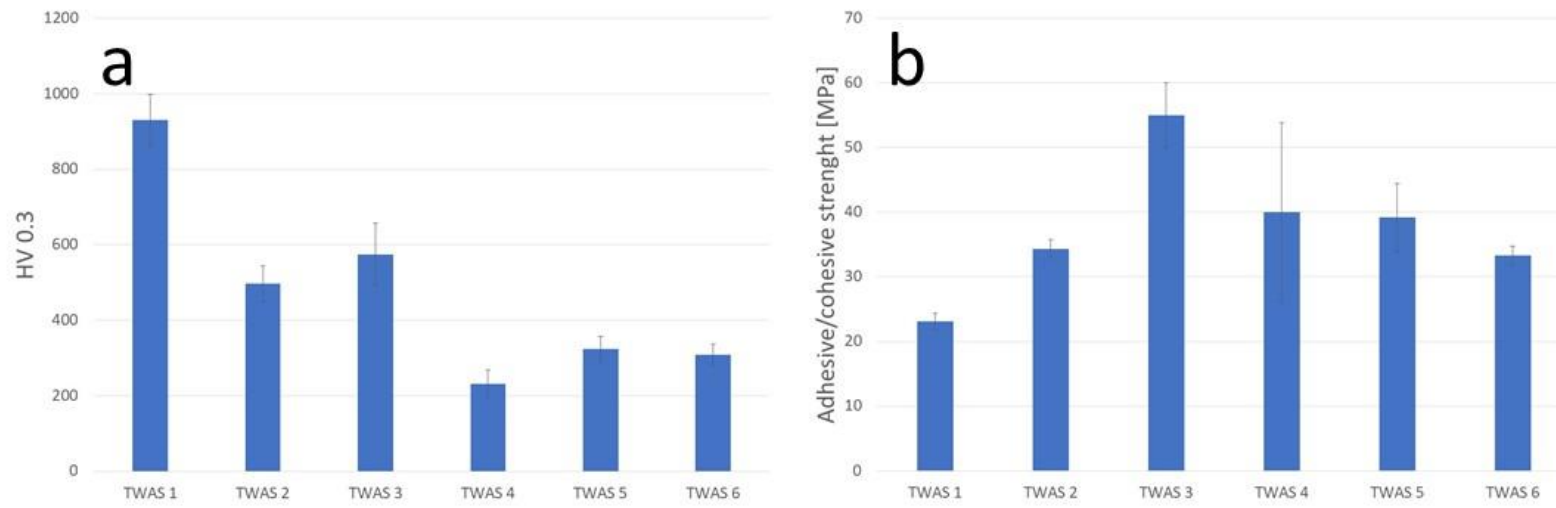

Figure 3 TWAS coatings HV0. 3 microhardness (a) and cohesive strength (b)

The abrasive wear resistance of TWAS sprayed coatings follows the trend of microhardness, even though the cohesive strength also takes part. The most resistant was the TWAS 3 coating, with highest cohesive strength and second highest microhardness, followed by the hard TWAS 1. On the contrary, the least abrasive wear 
resistance was found by the softest $\mathrm{NiCr}$ coating. There were no significant differences between in abrasive wear resistance of cold sprayed coatings. However, it is worth to mentioned, that their resistance in this type of load was lower compared to TWAS sprayed $\mathrm{NiCr}$ coating.

The solid particle erosion resistance is affected mostly by the toughness of coating material and its cohesive strength. Coatings from brittle materials or coating with low intersplat cohesion exhibit higher erosion rates at perpendicular impact of erosive particles. The wear mechanism is more brittle, the cracks and delamination of coatings material appears. On the contrary, softer but more ductile coatings materials exhibit higher volume losses in case of angled impact of erosive particles. The wear mechanism is in this case similar to the abrasive wear [5].

The results of solid particle testing in the range of this study confirms above mentioned expectations. The less erosion resistant material was hard and brittle TWAS 1, while the most resistant was tough TWAS 6 . The TWAS 4 ( $\mathrm{NiCr}$ ) was the second most resistant. Both TWAS 4 and TWAS 6 , showed ductile behavior - the lowest volume loss at perpendicular impact of erodent, the highest at low angled impact of erodent. The volume loss of cold sprayed (CS) specimens was generally one magnitude lower compared to TWAS coatings. There was some observed difference between the CS sprayed coatings observed. The best behavior was recorded for coating, deposited from finer particles, while the lowest resistance was recorded for coatings deposited at $45^{\circ}$ angle. The eroded surfaces of brittle TWAS 1 and ductile CS after the impact at low and high angles, are displayed in the Figure 4.
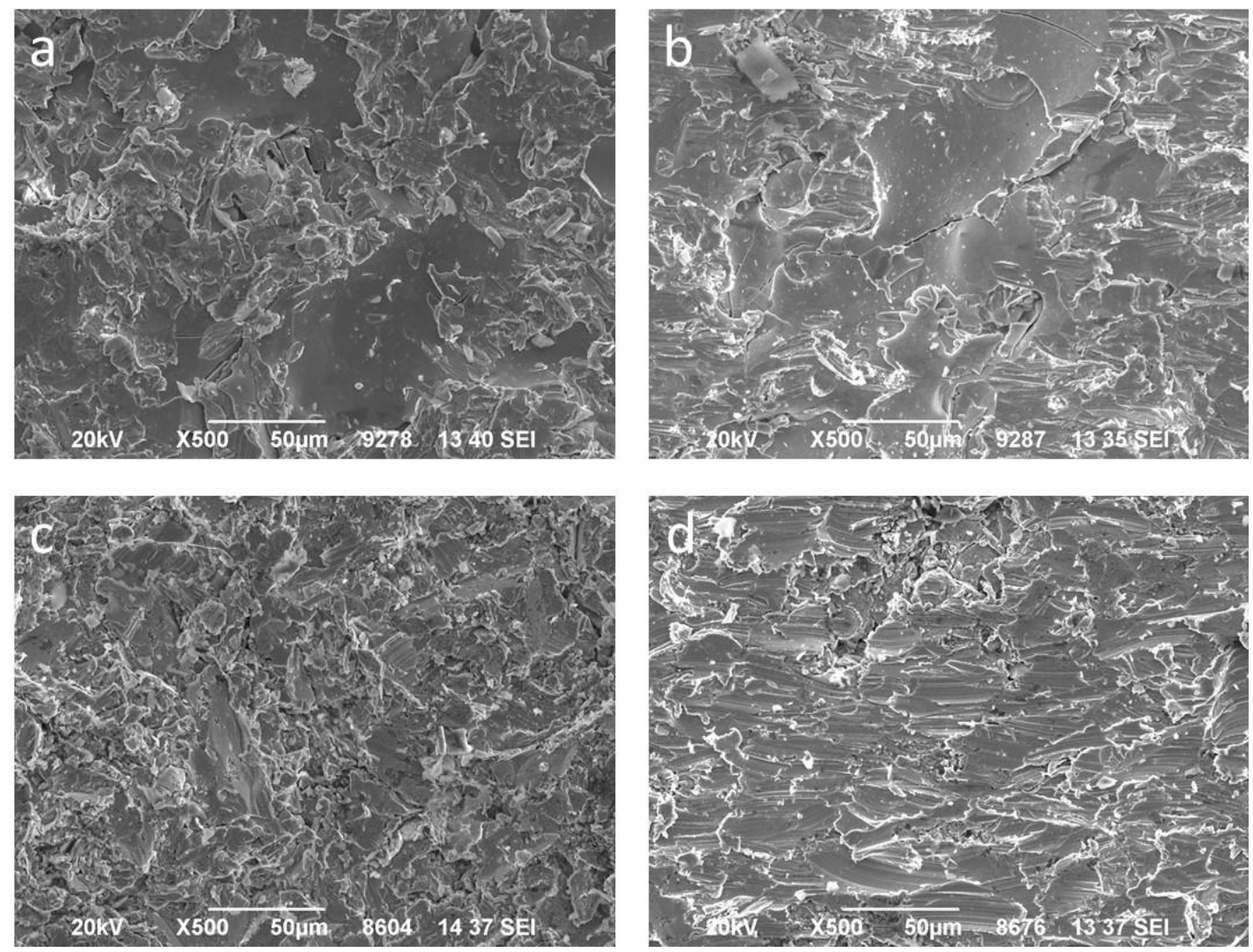

Figure 4 SEM of eroded surfaces of TWAS 1 - 90 impact angle (a); TWAS 1 - $15^{\circ}$ impact angle (b); CS - $90^{\circ}$ impact angle (c); CS - $15^{\circ}$ impact angle (d)

The preliminary results of high temperature corrosion tests in the aggressive environment simulating the atmosphere of solid fuel boilers confirms the protective properties of $\mathrm{NiCr}$-based coatings. Negligible corrosion was recorded for $\mathrm{CS} \mathrm{NiCr}$ coatings, little bit more pronounced corrosion was identified in case of TWAS NiCr 
coatings. The experimental evaluation of Fe-based coatings is not finished yet. With respect to higher $\mathrm{Cr}$ content in TWAS 1 composition, the higher corrosion resistance can be expected. Nevertheless, under the real working condition, the combined erosion-corrosion can led to different conclusions.

To evaluate the protective ability of the coatings under the real conditions, certain areas of boiler K21 in coalfired power plant Tušimice II were coated by selected TWAS deposited coatings The coating surfaces were further covered by protective paint (Figure 5). The results of long-term exposition (cca 1 year) will be known in 2021.
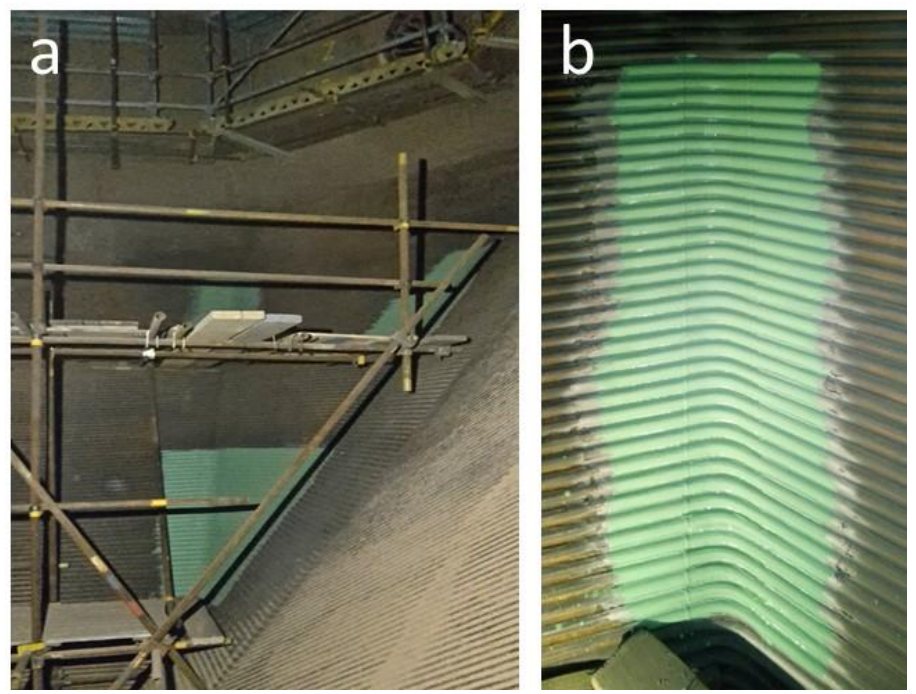

Figure 5 Scaffolding in the hopper area of boiler K21 ETU II (a); detail of coted area (b)

\section{CONCLUSION}

The preliminary results of the solved project showed a potential of Twin Wire Arc Spraying (TWAS) technology and Cold Spray (CS) technology to deposit thick coatings with properties, enabling protection of components in harsh environment. The relationship between the microstructure, mechanical properties and functional properties of coatings was shown. Following experimental program will focus on the cold sprayed coatings evaluation with respect to their potential for protection of heterogenous welds of pipes against corrosion.

\section{ACKNOWLEDGEMENTS}

\section{The paper has originated in the framework of the solution of the National Center for Energy project} no. TN01000007.

\section{REFERENCES}

[1] PAWLOWSKI, L. The Science and Engineering of Thermal Spray Coatings, John Wiley \& Sons, Ltd.,2008, second edition

[2] SIDHU, HS., SIDHU, BS., PRAKASH S. Comparative characteristic and erosion behavior of NiCr coatings deposited by various high-velocity oxyfuel spray processes, J. Mater. Eng. Perform., 2006, vol. 15, pp. 699-704

[3] POHKHMURSKI, V., STUDENT, M., GVOZDECKII, V. et al. Arc-Sprayed Iron-Based Coatings for ErosionCorrosion Protection of Boiler Tubes at Elevated Temperatures. J Therm Spray Tech, 2013, vol. 22, pp. 808-819

[4] ČESÁNEK, Z., HOUDKOVÁ, Š., LUKÁČ, F. High-temperature corrosion behavior of selected thermally sprayed coatings in corrosive aggressive environment. Materials Research Express, 2019, vol. 6, article no. 016426

[5] KULU, p., HUSSAINOVA, I., VEINTHAL, R. Solid particle erosion of thermal sprayd coatings, Wear, 2005, vol. 258, pp. 488-469 